\title{
CARROS ELÉTRICOS NAS REGIÕES SUL, SUDESTE E CENTRO- OESTE: IMPACTOS NA REDE ELÉTRICA
}

\section{ARTIGO ORIGINAL}

GONÇALVES, Matheus de Marco ${ }^{1}$

LIMA, Marcos Nogueira de ${ }^{2}$

FAESARELLA, Annete Silva ${ }^{3}$

SABLÓN, Vicente Idalberto Becerra ${ }^{4}$

GONÇALVES, Matheus de Marco. Et al. Carros elétricos nas regiões Sul, Sudeste e Centro-Oeste: Impactos na rede elétrica. Revista Científica Multidisciplinar Núcleo do Conhecimento. Ano 05, Ed. 10, Vol. 15, pp. 127-150. Outubro de 2020. ISSN: 24480959, Link de acesso: https://www.nucleodoconhecimento.com.br/engenhariaeletrica/rede-eletrica

\section{RESUMO}

Com o meio ambiente sendo um assunto em pauta ao redor do mundo, muito se discute sobre soluções para redução de emissões de gases de efeito de estufa e a redução da utilização de combustíveis fosseis para geração de energia. Com essa preocupação, uma das soluções adotadas é a utilização de carros elétricos e o fato de vários países desenvolvidos já trabalharem com leis para proibir a produção de carros à combustão dentro dos próximos vinte anos. No Brasil a venda de carros elétricos ainda está na fase inicial e pouco se verifica o incentivo do governo para alavancar esse tema. Porém pensando em um crescimento futuro desta tecnologia

\footnotetext{
${ }^{1}$ Graduação em Engenharia Elétrica pela Universidade São Francisco - USF.

${ }^{2}$ Graduação em Engenharia Elétrica pela Universidade São Francisco - USF.

${ }^{3}$ Orientadora. Doutora. Professora da Universidade São Francisco - USF.

${ }^{4}$ Doutor. Professor da Universidade São Francisco - USF.
} 
este artigo verifica quais são os impactos causados no balanço energético e nas subestações de distribuição de energia elétrica, com a análise dos problemas que os carros elétricos podem trazer se o número de consumidores residenciais aumentar consideravelmente. Como resultado dessa análise, o artigo conclui que o Brasil tem sua capacidade instalada de geração de energia capaz de suportar a futura frota de veículos elétricos, porém isso só será possível se um replanejamento de produção de energia fosse efetuado. $\mathrm{O}$ artigo apresenta também a indicação dos pontos referentes à infraestrutura do SIN - Sistema Interligado Nacional necessita ser redimensionado ou replanejado, para que se possa alimentar a futura frota de veículos elétricos do Brasil. Todo o estudo para indicação de soluções para o problema da demanda de energia elétrica frente a futura frota de veículos elétricos foi fundamentado em simulações com o software ETAP 16.1.0 e também foram verificados os possíveis distúrbios que o carregamento dos veículos elétricos podem causar nos sistemas elétricos. Todos os dados referentes à subestação de energia elétrica utilizados nas simulações desse trabalho foram fundamentados numa subestação física existente no sistema da CPFL - Companhia Paulista de Força e Luz.

Palavras-chave: Frota de veículos elétricos no Brasil, subsistema Sudeste/CentroOeste de energia elétrica, recarga de veículos elétricos.

\section{INTRODUÇÃO}

O crescimento de carros elétricos (EVs - electric vehicles) e híbridos no mundo é muito considerável para o futuro. Muitos estudos estão sendo realizados afim de desenvolver um sistema com autonomia satisfatória para as distâncias sendo percorridas pelos EVs, um dos grandes desafios é desenvolver baterias com maior autonomia e maior durabilidade. Os carros elétricos podem ser divididos, principalmente, em quatro tipos: os totalmente elétricos (BEV- Battery Electric Vehicle), os híbridos (HEV - Hibryd Electric Vehicle), os híbridos com carregamento externo (PHEV - Plug-In Hibryd Electric Vehicle) e os veículos com células de combustível (FCEV - Fuel Cell and Battery Electric Vehicle) (TIE; TAN, 2013). 
A expansão do mercado mundial dos EVs é de extrema importância e inevitável por estar diretamente ligada à diminuição de poluentes no meio ambiente, assim como à diminuição do consumo de combustíveis fósseis já que os mesmos não são renováveis e possuem uma limitação em sua exploração.

Este trabalho tem por objetivo estudar a influência dos EVs alimentados pelo sistema elétrico de potência e se o atual subsistema, Sul e Sudeste/Centro-Oeste, é suficiente para a suportar a demanda dos EVs futuramente existente nessas regiões. Com o aumento da quantidade dos EVs as redes elétricas terão uma carga temporária ligada (tempo de carregamento) a ela muito maior do que a atual o que pode causar alguns distúrbios na mesma, fazendo com que sejam necessárias modificações na operação, no planejamento e na produção de energia do sistema elétrico.

Atualmente sabe-se que o sistema elétrico existente não é suficiente para suprir uma grande frota de EVs, sendo assim haverá necessidade de um planejamento para verificar quais as melhores opções futuras para que o uso dos EVs seja possível, ajudando assim a diminuição de poluentes gerados pelos carros. Porém, para esse planejamento, não se pode levar em consideração somente números ou emissão de poluentes, pois cada país tem um valor específico para investir em matriz energética, com isso deve atentar-se na questão econômica, recursos disponíveis e viabilização de novas malhas de rede elétrica (ARAÚJO; TIAGO, 2017).

No final do trabalho é apresentado uma ou mais soluções para suprir a demanda necessária de energia elétrica (EE - electrical energy) para uso de EVs em grande escala, fazendo o dimensionamento de rede e cabos de acordo com a quantidade de carga exigida por região. Dentro dos resultados são apresentadas algumas ideias de instalações de pontos de carregamento em lugares específicos como shoppings, estacionamentos privados, entre outros lugares públicos, bem como planos de incentivos para uma utilização inteligente dos pontos de recarga seguindo padrões de países mais desenvolvidos neste assunto.

Para fazer o estudo foram realizadas projeções gráficas sobre a quantidade de EVs, mapas da matriz energética da região sul e sudeste atual e planejada, estudos para 
melhoramento das tecnologias dos meios de geração de energia elétrica. As simulações necessárias para o estudo e análise dos dados foram realizadas com software ETAP 16.1.0 especializados em cálculos de demanda de EE, já considerando distúrbios gerados por qualquer tipo de carga e também focando nos distúrbios específicos gerados pelos EVs. Os dados da subestação são fundamentados em uma instalação da CPFL, fazendo com que o estudo se aproxime ao máximo da realidade (CPFL, 2018).

\section{CARRO ELÉTRICO (EV)}

\section{HISTÓRIA}

O surgimento dos veículos elétricos aconteceu por volta do ano de 1837, quando Robert Davidson de Aberdeen criou uma carruagem elétrica utilizando uma célula galvânica de ferro-zinco e um motor elétrico. Já em 1859 o físico francês Gaston Planté inventou a bateria recarregável de chumbo-ácido, viabilizando assim o armazenamento de eletricidade a bordo de um veículo, porém a bateria recarregável se tornou um item comercializado apenas em 1881. Com todos esses avanços tecnológicos a London Electric Cab Co. Ltd. iniciou a produção de táxis na Inglaterra no ano de 1897. No final do século XIX os carros elétricos representavam mais de um quarto dos veículos de transportes mundiais.

No começo do século $X X$ os carros elétricos começaram a diminuir drasticamente nas ruas, alguns fatores que contribuíram para o crescimento da popularidade e viabilidade dos carros com motor a combustão (ICE) foram: a invenção do motor de partida, o barateamento no custo do petróleo, baixa autonomia e velocidade dos EVs, entre outros fatores. Com isso, no ano 1935 não se tinha mais nenhum EV nas ruas do mundo.

O início da retomada dos carros elétricos ocorre na década de 70 quando alguns países começam a se preocupar muito com a poluição ambiental e o surgimento da crise na indústria petrolífera, fazendo com que as montadoras e novas empresas voltassem a pensar no desenvolvimento de EVs. Porém alguns pontos precisavam 
ser corrigidos nos projetos para que os veículos elétricos possam competir a altura dos ICEs, como a baixa autonomia, velocidade reduzida, demora no carregamento e falta de estrutura.

Em 1996 a General Motors Corporation produziu o modelo EV1, sendo o primeiro carro híbrido. Enquanto em 1997 a Toyota Motors Corporation iniciou a produção do Prius, sendo os primeiros HEVs do mundo. Com o passar dos anos e novas regras de emissão de poluentes sendo discutidas pelos países, outras indústrias automotivas também desenvolveram seus carros elétricos e a tendência é que a quantidade de EVs aumente cada vez mais.

\section{TECNOLOGIAS EM EVS}

Um dos EVs mais comuns hoje nas ruas são os carros híbridos, para ele ser considerado híbrido é necessário que ele possua duas ou mais fontes para gerar energia. A configuração utilizada, para os carros híbridos atuais, é com um motor de combustão e outro motor elétrico. Os HEVs podem ser classificados em quatro tipos, como visto nas Figuras 1 e 2.

Figura 1 - Classificação dos HEVs. (a) série (acoplamento elétrico) ;(b) paralelo (acoplamento mecânico)

(a)

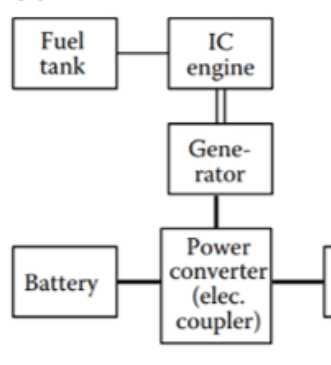

(b)

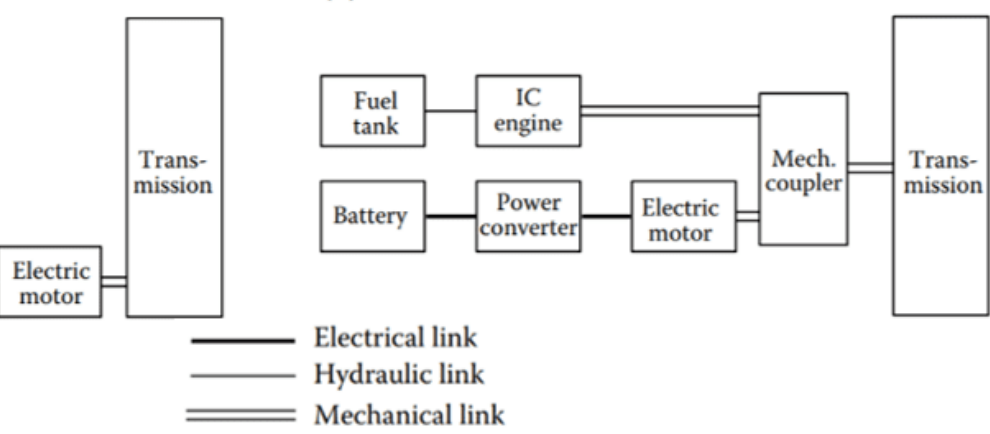

Fonte: CHAN, C. C. e CHAU, K.T, 2001 
Figura 2 - Classificação dos HEVs. (c) série-paralelo (acoplamento mecânico e elétrico); (d) complexo (acoplamento mecânico e elétrico)

(c)

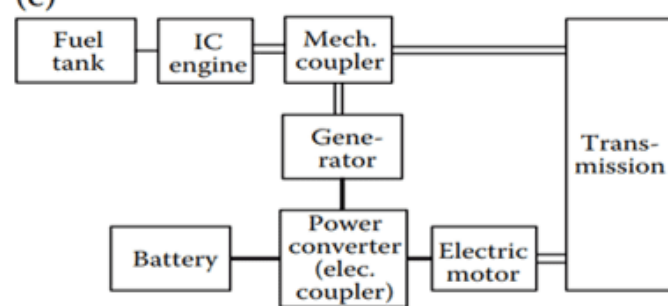

(d)

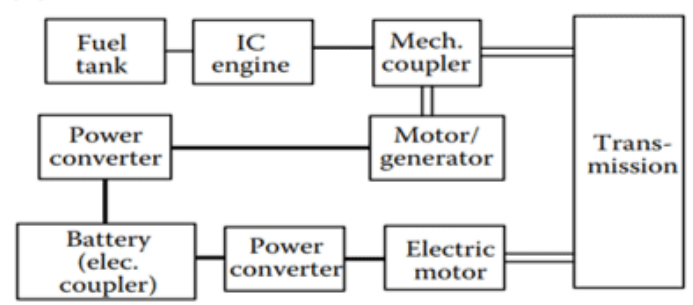

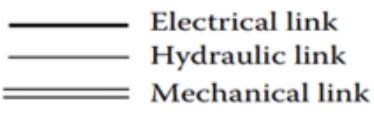

Fonte: CHAN, C. C. e CHAU, K.T, 2001

Quando o HEV possui uma configuração em série a única fonte de propulsão é o motor elétrico (EM - Electric Motor), enquanto o motor a combustão e os freios regenerativos servem para recarregar a bateria quando está com baixa carga. Este tipo de carro é eficiente em um cenário de condução dentro da cidade onde o carro tem uma rotina de anda e para frequente. A economia de combustível pode ser de até $25 \%$ comparado com carros convencionais, além de ser um sistema simples para criar o design, controlar e implementar (TIE e TAN, 2013).

Já na configuração paralela de um HEV, temos o motor de combustão (ICE - Internal Combustion Engine) e o motor elétrico como fonte de tração para o carro, normalmente utilizando o ICE como fonte principal e o motor elétrico apenas como auxiliar.

No caso de um HEV série-paralelo é um sistema que pode atuar alguns momentos em paralelo e em outros em série, alternando o tipo de configuração para o melhor rendimento do carro. O problema deste sistema é que ele é mais caro e com um design mais complicado (YONG et al, 2015). Para o carro híbrido classificado com um sistema complexo, temos um sistema similar ao série-paralelo, só que o carregamento da bateria é feito separadamente por dois conversores de energia. 
Estas são as arquiteturas internas dos HEV, porém temos os modelos que possibilitam o carregamento externo da bateria também conhecidos com (PHEV - Plug-In Hibryd Electric Vehicle). Nestes modelos têm-se um carregar a mais ligado a bateria internamente e com uma tomada externa para conectar à rede de transmissão.

Outro tipo de EVs, que as montadoras estão focando bastante no desenvolvimento de melhorias, são os carros totalmente elétricos (BEV - Battery Electric Vehicle) onde a única fonte propulsão é o motor elétrico. As baterias são carregadas através de tomadas externas e sistema de freios regenerativos, onde a energia cinética gerada na frenagem é convertida em energia elétrica para carregar a bateria (YONG et al, 2015). Na Figuras 3 e 4 tem-se dois modelos de BEV, um que já está disponível para compra no Brasil e o outro que se tem a perspectiva da possibilidade de compra no Brasil em breve, respectivamente.

Figura $3-\mathrm{BMW}$ i3

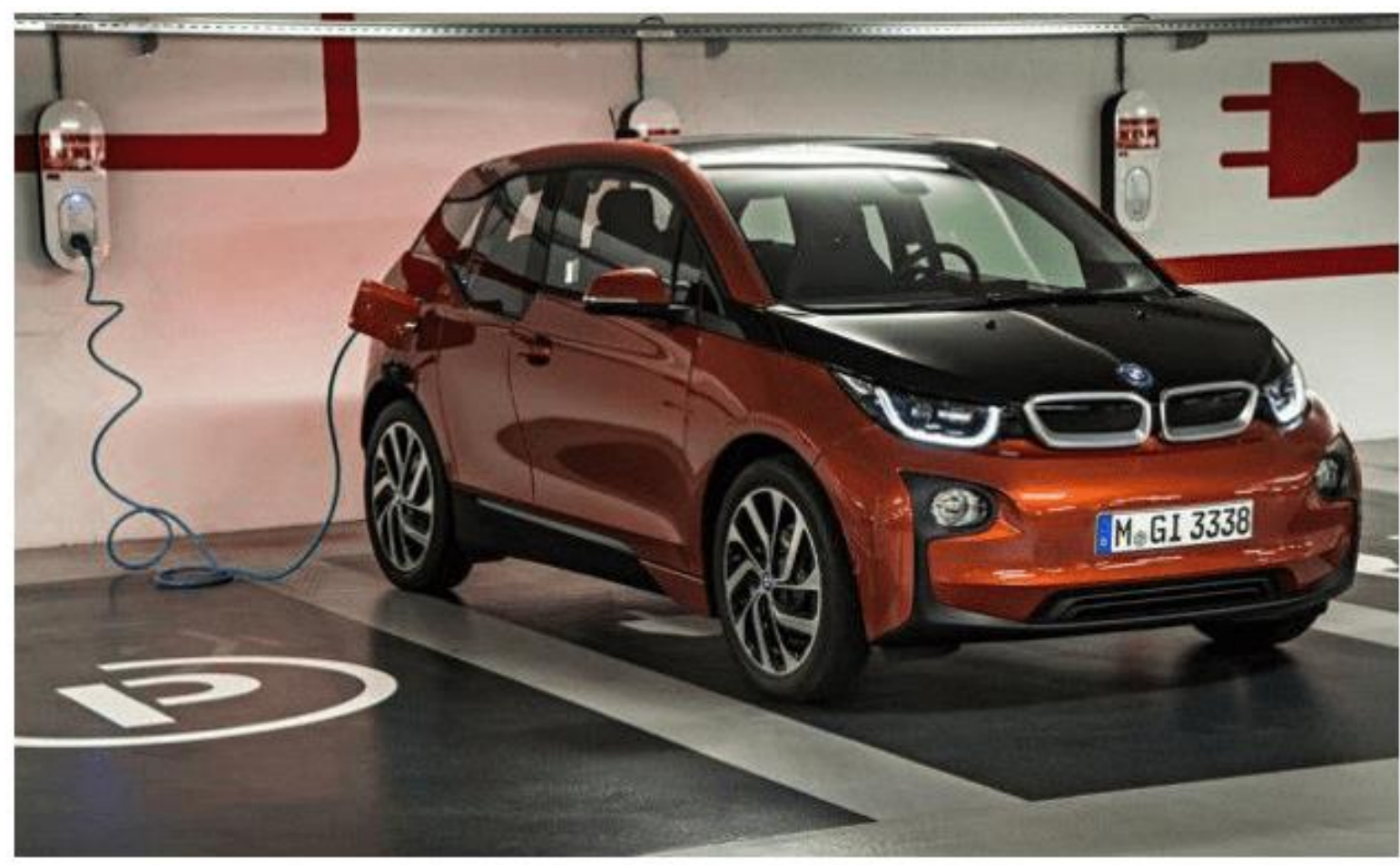

Fonte: JORNAL O SUL, 2018I 
Figura 4 - Renault Zoe

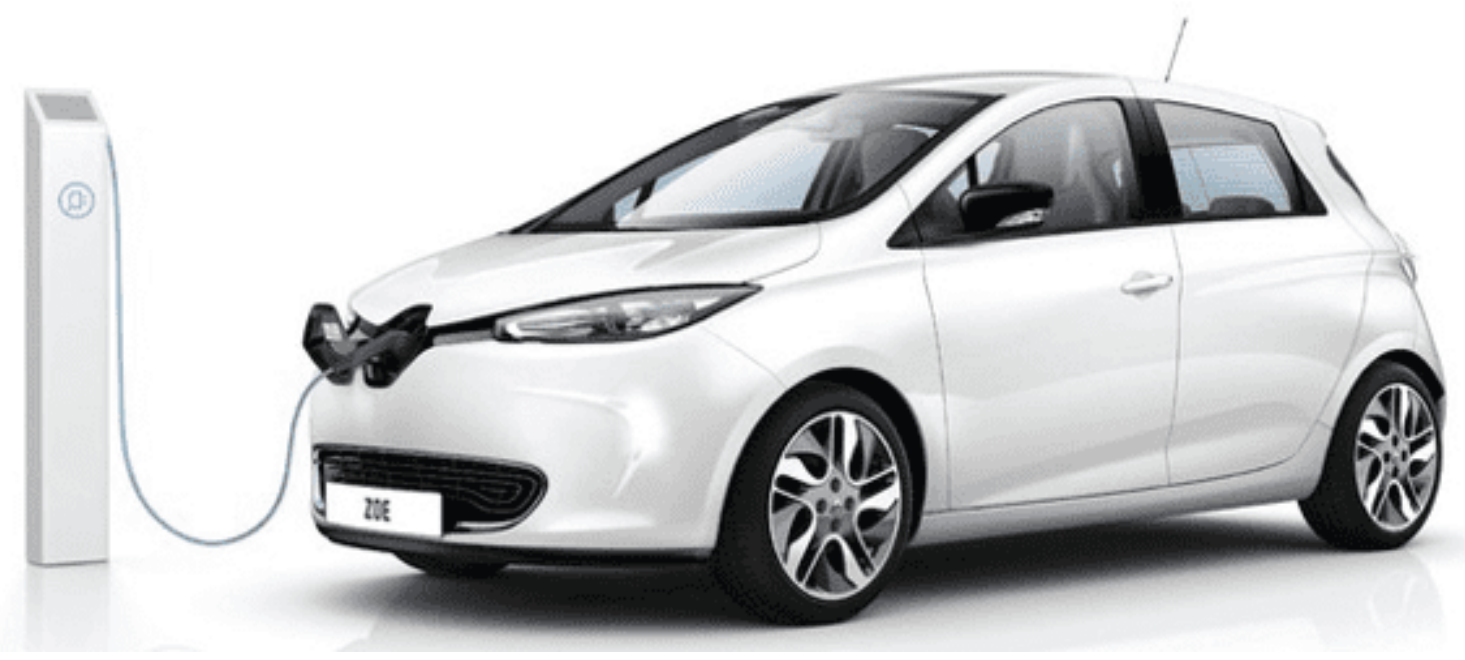

Fonte: REVISTA AUTO ESPORTE, 2018

O grande desafio dos EVs são as baterias, por isso existem mais de um tipo de bateria sendo usada pelas fabricantes de carros elétricos. Além das baterias, também existem estudos para o uso de super capacitores e células de combustíveis, e essas três fontes de energia podem trabalhar integradas. Essa combinação possibilita uma melhor eficiência no uso da energia demandada pelos EVs.

A escolha da melhor tecnologia a ser utilizada depende de alguns fatores como custo, confiabilidade, manutenção, tempo de vida, compactação, etc. Porém para auxiliar nesta escolha pode-se utilizar o gráfico de Ragone das fontes. Como mostrado na Figura 5, o gráfico de Ragone faz a comparação entre a energia disponível na fonte e a potência requerida constantemente pela carga, no nosso caso de estudo os carros elétricos (LOPES, 2012). 
Figura 5 - Gráfico de Ragone considerando diferente tipos de fontes de energia.

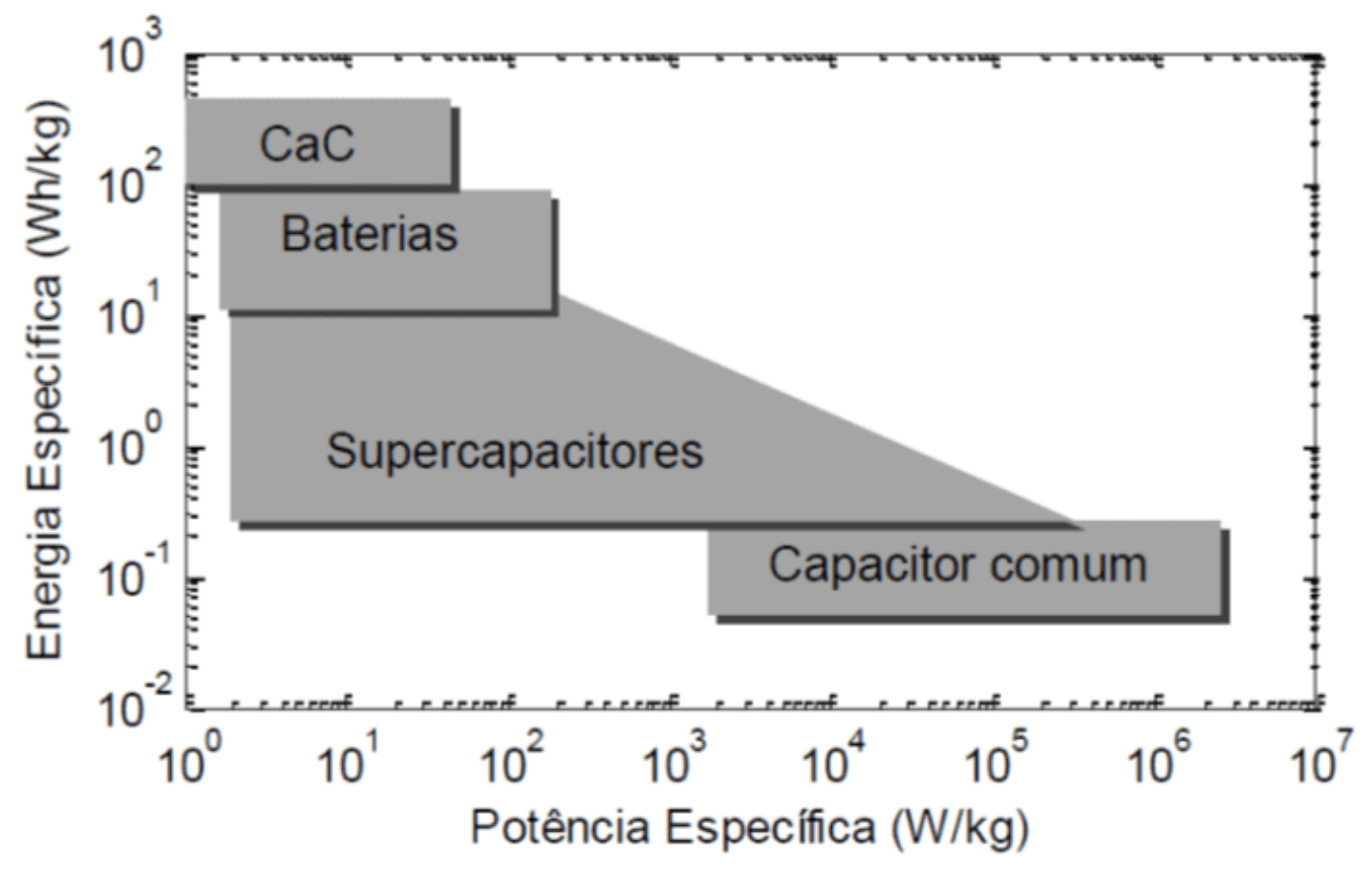

Fonte: LOPES, J., 2012

\section{MODOS DE CARREGAMENTO}

Atualmente são utilizados quatro modos de carregamento para os carros elétricos, sendo que os dois primeiros modos consistem em uma carga lenta através de uma tomada padrão.

Na Figura 6(a), temos o modo 1 onde o carro é ligado diretamente a rede elétrica com tomadas com no máximo 16A e $230 \mathrm{~V}$ monofásicos. Este modo tem a vantagem de ser simples, mas possui algumas desvantagens como: falta do sistema de proteção para curto-circuito e superaquecimento, entre outras. Na Figura 6(b), temos o modo 2 que possui uma ideia parecida com o modo 1, porém entre a tomada e o carro existe um bloco de controle, trazendo maior proteção e segurança para o sistema. 
Figura 6 - Modo de carregamento 1 e 2

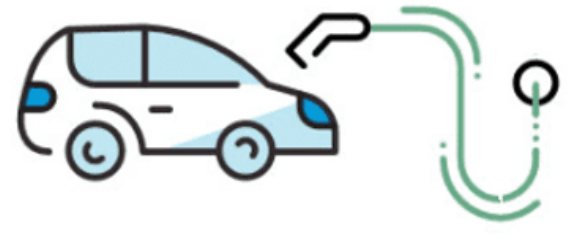

(a)

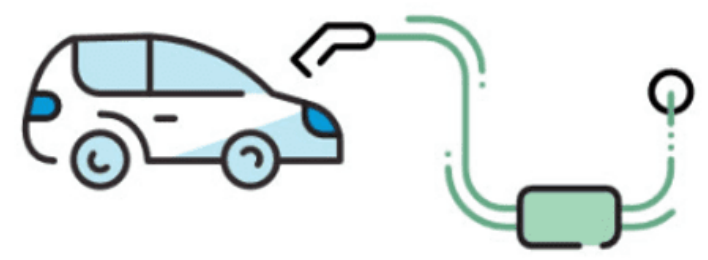

(b)

Fonte: Adaptado de ORANGE \& ROCKLAND, 2018

O terceiro modo de carregamento, da Figura 7(a), é um dos mais conhecidos e possui um conector com pinos específicos que permitem a comunicação bidirecional entre o EV e tomada, fazendo com que o ponto de carregamento só fique energizado com a presença de um EV. O tempo de carga depende do modelo do EV, mas em geral a carga completa demora em torno de 2 a 8 horas.

O quarto modo de carregamento, da Figura $7(\mathrm{~b})$, é conhecido como postos de carregamento rápido, onde pode carregar até a $80 \%$ da capacidade da bateria em um intervalo de tempo de 20 e 60 minutos através de uma carga em corrente contínua. Por ser um método de carregamento rápido é a opção mais viável para os lugares públicos, porém o custo de infraestrutura é mais elevado pois necessita do conversor CA-CC (ARAÚJO, 2017).

Figura 7 - Modo de carregamento 1 e 2

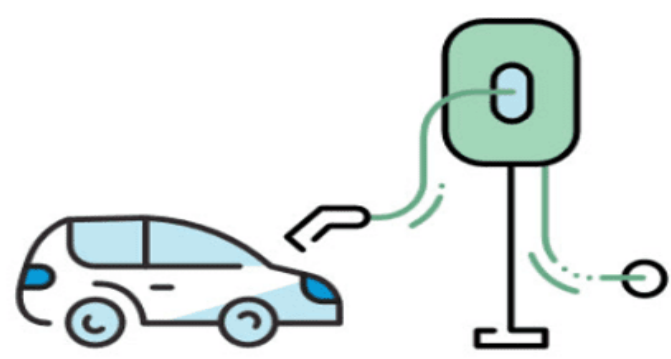

(a)



(b)

Fonte: Adaptado de ORANGE \& ROCKLAND, 2018 
Hoje a montadora que está mais avançada nos estudos referentes a bateria dos EVs é a Tesla Motors que utiliza uma tecnologia chamada de supercharger que através de um protocolo de carregamento CHAdeMO é possível que em 30 minutos de carregamento o carro tenha uma autonomia de $270 \mathrm{~km}$, sem prejudicar a vida útil da bateria (ARAÚJO, 2017).

\section{SISTEMA ELÉTRICO NO BRASIL}

O Brasil possui um sistema de geração e transmissão totalmente interligado de Norte a Sul, pequenas partes são denominadas como sistema isolados, entre tanto são sistemas que não apresentam carga ou geração significativa para o SIN. O sistema elétrico brasileiro é denominado como SIN - Sistema Nacional Interligado por ter todo o sistema de Geração e transmissão de energia elétrica interligado, o sistema é dividido em quatro subsistemas: Sul, Sudeste/Centro-Oeste, Nordeste e Norte. Esses Subsistemas são interligados pela malha de transmissão, essa configuração permite a transferência de energia entre subsistemas, proporcionando ganhos sinérgicos e também explora a diversidade entre os regimes hidrológicos das bacias.

As Usinas hidrelétricas contam com 16 bacias hidrográficas nas diferentes regiões do país, como o Brasil possui uma grande extensão territorial essas bacias se comportam de maneiras inversas entre as regiões Sul e Norte de acordo com a época do ano permitindo assim a variação de fluxo de energia de acordo com a capacidade de cada reservatório. Essa integração entre os sistemas de geração e transmissão permite o atendimento ao mercado com segurança e economicidade.

O Brasil possui quatro métodos de geração energia: hidrelétrico, eólico, térmico e solar com grande predominância no sistema hidrelétrico possuindo duas das maiores usinas hidrelétricas do mundo: Usina de Itaipu - Paraná (PR) e Usina de Belo Monte - Pará (PA).

O sistema de geração no ano de 2016 segundo a ONS foi operado da seguinte maneira: 71,6\% Hidroelétrico; 21\% térmica, sendo 8,7\% Term. Gás, 3,3\%Term. Óleo, 
2,2\% Term. Carvão, 5,4 \%Term. Biomassa e 1,4\% Term. Nuclear; 6,8\% eólica e 0,6\% outras.

De acordo com ONS o Brasil no ano de 2016 teve uma demanda média de 457.887GWh como um todo, sendo 268.084GWh (58,6\%) consumida apenas nos subsistemas Sudeste/Centro-Oeste, $82.063 \mathrm{GWh}(17,9 \%)$ consumida pelo sistema Sul, 73.307GWh (16\%) consumida pelo subsistema Nordeste e 34.433GWh $(7,5 \%)$ consumida pelo sistema Norte e toda essa geração conta com mais de $134.765 \mathrm{~km}$ de linha de transmissão para atender a demanda de carga.

Como a maior carga consumida fica nos subsistemas Sul e Sudeste/Centro-Oeste pode observar, de acordo com a Figura 8, que as principais linhas de transmissão visam atender tal subsistema.

Figura 8 - Redes de transmissão do SIN

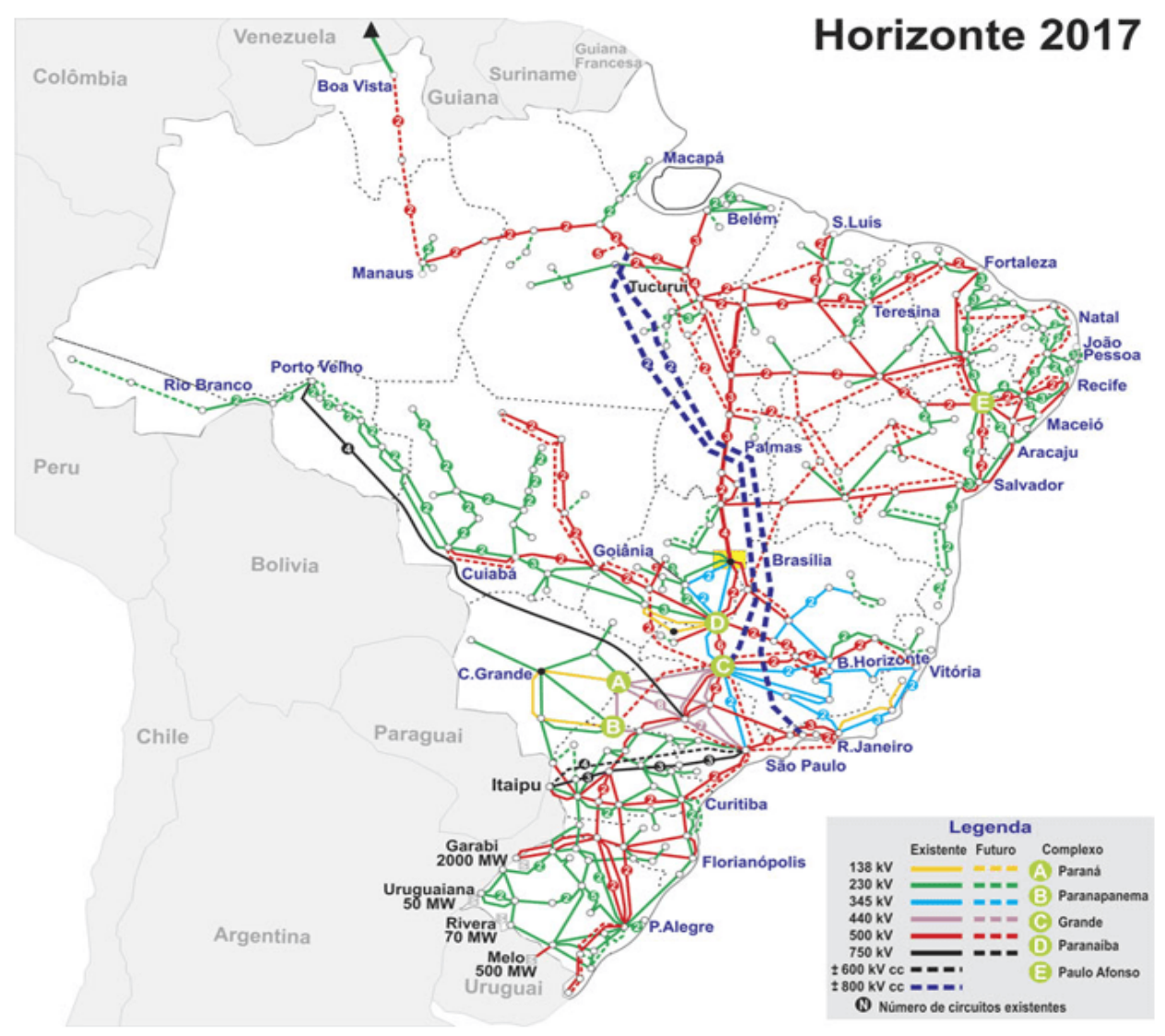

Fonte: ONS, 2018

RC: 63731

Disponível em: https://www.nucleodoconhecimento.com.br/engenharia-eletrica/rede-eletrica 


\section{METODOLOGIA}

Para iniciar o estudo do impacto dos EVs na rede elétrica foram definidos um modelo de EV para análise dos impactos durante todas as fases de carregamento. Dentro desta análise serão avaliadas as interferências geradas e a carga requerida pelo carro elétrico durante o carregamento, levando em consideração que os EVs podem possuir baterias e comportamentos diferentes. Esta análise pontual e individual será feita com os dados atuais fornecidos pelas fabricantes automotivas e as organizações que controlam a rede elétrica.

A quantidade de $E V$ levará em consideração uma porcentagem referente ao número de consumidores residenciais. A análise do balanço energético utiliza o valor de potência requerida pelo EV considerando o método de carregamento residencial e com maior demanda de carga.

Foi realizado também as simulações dos impactos EVs em uma rede de transmissão de média potência a partir dos dados disponíveis e utilizando o software ETAP 16.1.0 disponibilizado pela Universidade São Francisco, onde verificou-se o aumento de carga demandada no transformador. O software ETAP 16.1.0 é uma ferramenta que nos permite verificar o comportamento de sistemas elétricos a partir de dados parametrizados.

Durante as simulações foram considerados as premissas de que os resultados levam em consideração apenas carregamento do transformador, desconsiderando impacto da queda de tensão na rede de distribuição.

Com os resultados dos estudos de casos é possível verificar o aumento necessário no sistema de geração e transmissão nas regiões sul, sudeste e centro-oeste para uma melhor integração com os EVs. 


\section{RESULTADOS E DISCUSSÃO}

Através de pesquisas foram encontrados os modelos que temos de carros BEV e PHEV são mostrados na tabela 1. A tabela também mostra a capacidade de energia das baterias.

Tabela 1 - Modelos de EVs no Brasil

\begin{tabular}{|l|l|l|l|}
\hline Marca & Modelo & Tipo & Bateria (kWh) \\
\hline BMW & i3 (2014-2016) & BEV & 22 \\
\hline BMW & i3 (2017-) & BEV & 33 \\
\hline BMW & i8 & PHEV & 11,6 \\
\hline Chevrolet & Bolt & BEV & 60 \\
\hline Porsche & Cayenne E-Hybrid & PHEV & 14,1 \\
\hline Porsche & Panamera E-Hybrid & PHEV & 14,1 \\
\hline Tesla & Model 3 & BEV & 50 \\
\hline Tesla & Model S & BEV & 70 \\
\hline Volvo & XC90 T8 & PHEV & 9,2 \\
\hline
\end{tabular}

Fonte: próprio autor

Neste trabalho de graduação constatou-se que o dado de maior relevância é o tempo de carregamento da bateria do carro elétrico, bem como o método utilizado para esse fim, porém isso varia para cada modelo de carro e também qual o método de carregamento. Na Tabela 2 tem-se a carga para os três tipos de carregamento disponíveis do BMW i3 (2014-2016), BMW i3 (2017-) e BMW i8. Os valores na tabela referem-se ao tempo de carregamento completo da bateria.

Tabela 2 - Tempo de carga completa das baterias para os EVs da BMW

\begin{tabular}{|l|l|l|l|l|}
\hline Tomada & Fonte BMW & $\begin{array}{l}\text { Bateria } \\
(\mathrm{kWh})\end{array}$ & $\begin{array}{l}\text { Carregamento Total } \\
(\mathrm{hrs})\end{array}$ & $\begin{array}{l}\text { Carga necessária } \\
(\mathrm{kW})\end{array}$ \\
\hline $\mathbf{1 2 7 V}$ & & 22 & 18 & 1,22
\end{tabular}




\begin{tabular}{|l|l|l|l|l|}
\hline & $\begin{array}{l}\text { Occasional } \\
\text { Use Cable }\end{array}$ & 33 & 28 & 1,18 \\
\hline $\begin{array}{l}\text { UseV/20A } \\
\text { (OUC) }\end{array}$ & 11,6 & 7 & 1,66 \\
\hline & $\begin{array}{l}\text { TurboCord } \\
\text { Charger }\end{array}$ & 22 & 5 & 4,4 \\
\hline \multirow{2}{*20V/32A}{} & 33 & 8 & 4,13 \\
& Estação & 22 & 3 & 5,8 \\
\hline & carregamento & 33 & 4 & 7,33 \\
\hline & & 11,6 & 2 & 8,25 \\
\hline
\end{tabular}

Fonte: ELECTRIFY, I, 2018

Com a tabela 2 verifica-se que a estação de carregamento proporciona um tempo bem menor para carregar os EVs, porém demanda um equipamento específico e de alto valor agregado. Deste modo as estações de carregamento tendem a ser encontradas em espaços públicos e o carregamento residencial será feito através de método de carregamento mais demorado.

\section{ESTUDO DE CASO 1}

Coletando os dados dos subsistemas Sudeste/Centro-Oeste e Sul do "Anuário Estatístico de Energia Elétrica 2017 - ano base 2016" foi analisado o impacto do crescimento de EVs na demanda de energia. Na Figura 9 e Figura 10 foi considerado para o estudo o carro elétrico BMW i3 (2017-) onde as pessoas rodam em 50Km/dia, e como a autonomia deste carro é de $200 \mathrm{Km}$ chega-se no valor de um consumo anual por carro de $3.011 \mathrm{KWh}$. Também se considerou o número de consumidores residências por subsistema para pressupor a quantidade de EVs, no subsistema Sudeste/Centro-Oeste o número de consumidores é de 36.736 .666 e o subsistema Sul tem 9.746.164 consumidores. 
Figura 9 - Gráfico considerando o aumento de carga no subsistema Sudeste/CentroOeste devido ao aumento de EVs

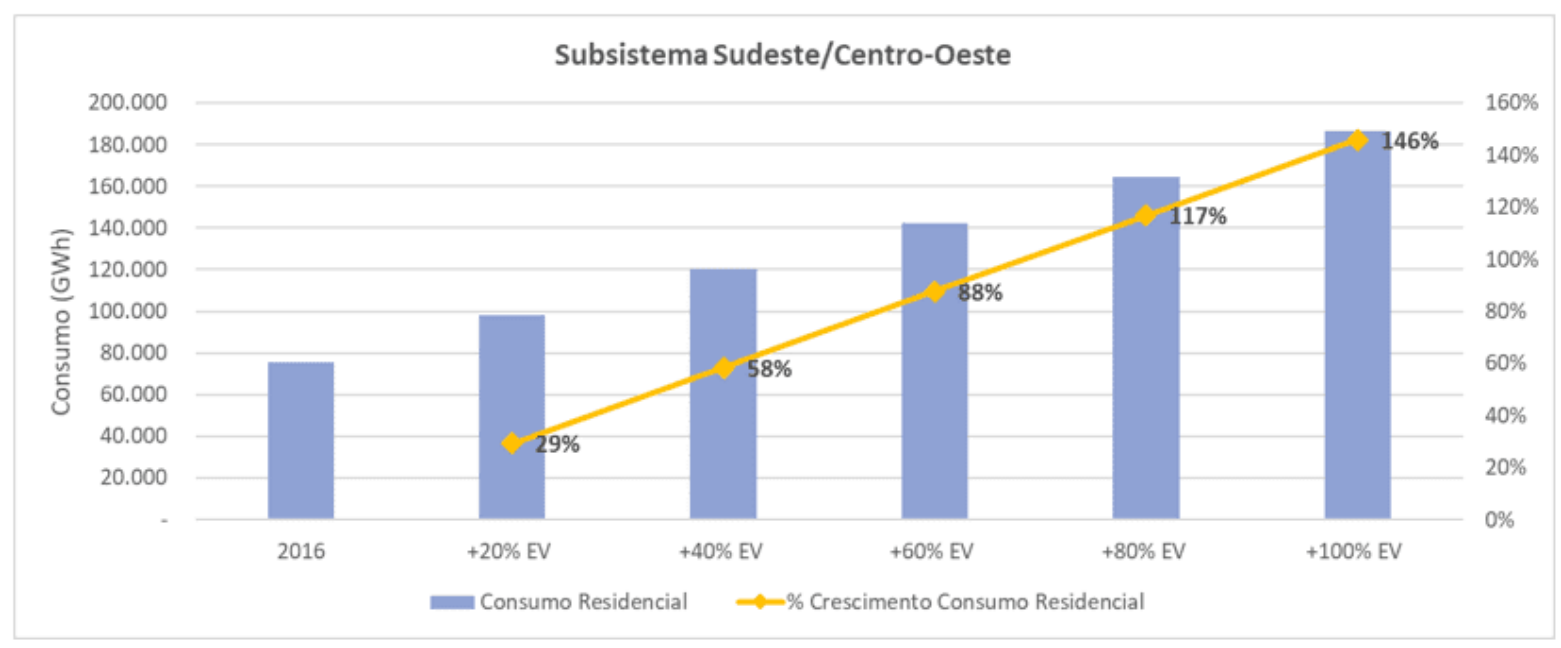

Fonte: próprio autor

Figura 10 - Gráfico considerando o aumento de carga no subsistema Sul devido ao aumento de EVs

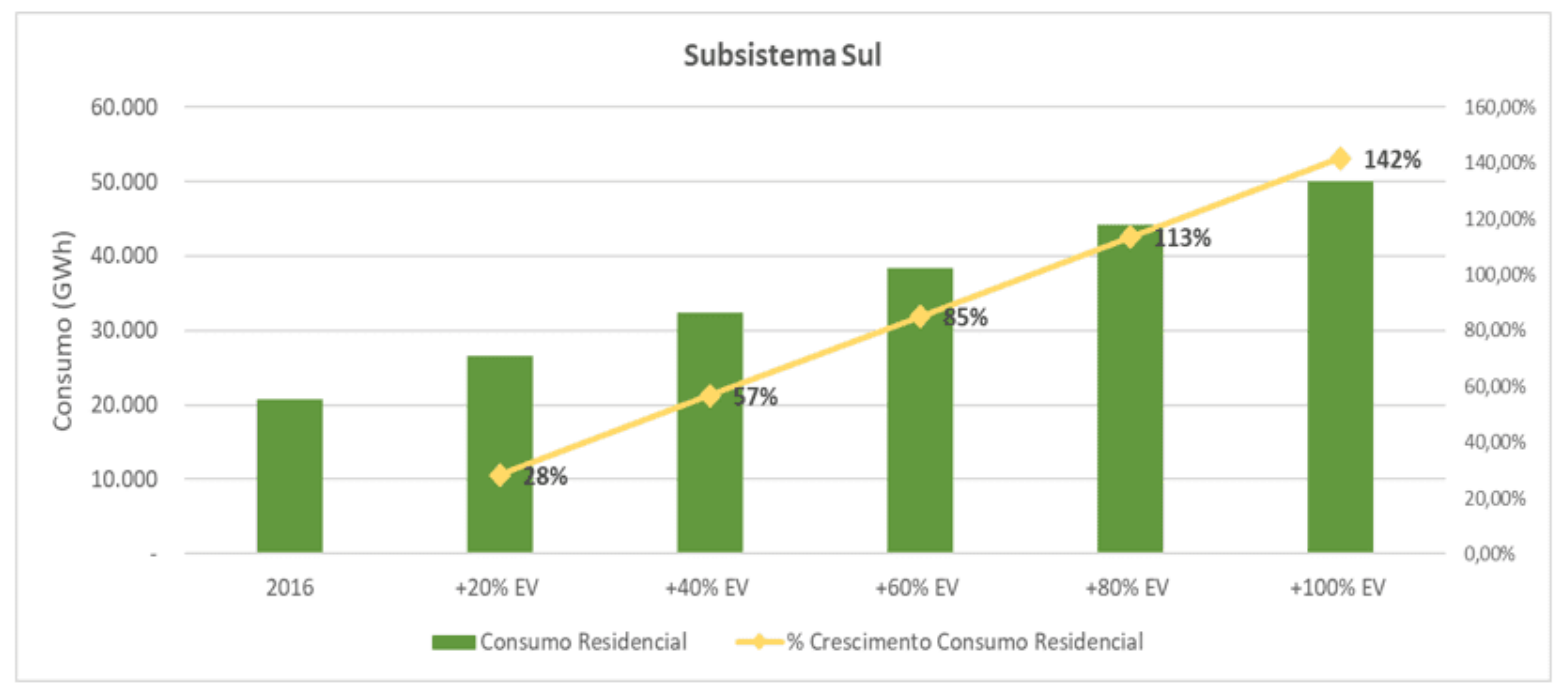

Fonte: próprio autor

Observa-se no gráfico dos dois subsistemas que o crescimento dos EVs aumenta o consumo consideravelmente, sendo que no cenário com acima de $60 \%$ dos consumidores residenciais carregando seus EVs tem-se um consumo próximo do 
dobro consumido no ano de 2016 e com 100\% da inserção dos EVs o crescimento do consumo anual ultrapassa os $140 \%$.

Levando em consideração o panorama nacional e a inserção dos carros elétricos apenas nos subsistemas Sudeste/Centro-Oeste e Sul obtém-se os valores da Figura 11

Figura 11 - Gráfico considerando o aumento de carga em âmbito nacional devido ao aumento de EVs nas regiões Sudeste, Sul e Centro-Oeste



Fonte: próprio autor

Pela Figura 11 é possível observar que, tomando como base ano de 2016, se neste ano todas as residências possuíssem um EVs e rodam-se $40 \mathrm{Km} /$ dia a energia gerada pelo nosso Sistema Interligado Nacional não seria o suficiente para alimentar a demanda nacional de energia.

\section{ESTUDO DE CASO 2}

De acordo com os dados técnicos disponibilizados pelo Eng. José Dirceu, obtivemos acessos aos parâmetros técnicos de uma Subestação (SE) típica pertencente a 
Companhia Paulista de Força e Luz - Paulista (CPFL- Paulista). Com estes dados, as simulações e análise tendem a ser mais próximas do cenário real.

A subestação utilizada para os estudos é uma SE com característica de 5 patamares sendo composta de um transformador abaixador de tensão com potência nominal de 26,6MVA; $138 / 11,9 \mathrm{KV}$. O transformador alimenta uma barra de 11,9KV que interliga 5 alimentadores com cargas distintas. A Tabela 3 mostra os dados do transformador e Tabela 4 apresenta os valores de potência ativa e reativa na carga considerando a configuração atual da SE.

Tabela 3 - Dados técnicos do transformador

Subestação CPFL

\begin{tabular}{|c|c|c|c|c|c|}
\hline Equip. & $\begin{array}{l}\text { Pot. } \\
\text { Nominal }\end{array}$ & $\begin{array}{l}\text { Tensão } \\
\text { Nominal }\end{array}$ & Carga total & Carregamento & FP \\
\hline \multirow[t]{3}{*}{ Trafo 1} & \multirow[t]{3}{*}{ 26,6MVA } & \multirow[t]{3}{*}{$138 / 11,9 \mathrm{KV}$} & $\mathrm{S}=23 \mathrm{MVA}$ & \multirow[t]{3}{*}{$87 \%$} & \multirow[t]{3}{*}{$95 \%$} \\
\hline & & & $P=22 M W$ & & \\
\hline & & & $\mathrm{Q}=7 \mathrm{MVAr}$ & & \\
\hline
\end{tabular}

Fonte: (CPFL, 2018)

Tabela 4 - Dados da configuração atual da SE

\begin{tabular}{|l|l|l|l|l|l|}
\hline Alimentador & $\begin{array}{l}\mathrm{n}^{-} \\
\text {consumidores }\end{array}$ & $\begin{array}{l}\text { Potência na } \\
\text { Carga }(\mathrm{KW})\end{array}$ & $\begin{array}{l}\text { Potência } \\
\text { Reativa } \\
\text { Carga (KVAr) }\end{array}$ & $\begin{array}{l}\text { FP } \\
(\%)\end{array}$ & $\begin{array}{l}\text { Distancia } \\
(\mathrm{m})\end{array}$ \\
\hline alim01 & 1514 & 5469 & 1804 & 94,97 & 9.171 \\
\hline alim02 & 8416 & 5038 & 2022 & 92,81 & 27.108 \\
\hline alim03 & 7776 & 5351 & 2436 & 91,01 & 30.006 \\
\hline alim04 & 6376 & 3071 & 457 & 98,91 & 25.828 \\
\hline alim05 & 6052 & 2977 & 427 & 98,99 & 18.746 \\
\hline
\end{tabular}

Fonte: (CPFL, 2018) 
A Tabela 5 mostra os valores de carregamento do EV Renault Zoe com um comportamento de carregamento em carga lenta linear, estes foram os valores considerados durante os cenários de simulações.

Tabela 5 - Dados técnicos do BEV Renault Zoe

\begin{tabular}{|l|l|l|l|}
\hline Modelo & Potência (KW) & Potência Reativa (KVAr) & FP \\
\hline Renault ZOE & 3 & 1,4 & $92 \%$ \\
\hline
\end{tabular}

Fonte: (REVISTA AUTO ESPORTE, 2018)

Foram realizadas 3 simulações, sendo que em cada uma delas foi considerado um aumento de $5 \%$ a mais de consumidores utilizando carros elétricos, sempre levando em consideração que o carregamento desses EVs é realizado em horários de ponta. As potências tiveram um comportamento basicamente linear, sem grandes variações.

Durante as análises foi considerado o cabo A336 que possui como fator limitante uma corrente máxima de 515 amperes (A). A escolha desse cabo deve-se a grande utilização do mesmo em redes de distribuição da CPFL. Outro fator limitante que verificado foi o transformador com potência aparente máxima de 26,6 MVA.

Na primeira simulação considera-se que $5 \%$ dos consumidores utilizam EVs e o carregamento deles são efetuados ao mesmo tempo. Os valores parametrizados são mostrados na Tabela 6 e os resultados são observados nas Figuras 12 e 13.

Tabela 6 - Dados da SE com 5\% dos consumidores carregando seus BEV

\begin{tabular}{|l|l|l|l|l|l|l|}
\hline Alimentador & $\begin{array}{l}n^{\circ} \\
\text { cons. }\end{array}$ & $\begin{array}{l}\mathrm{n}^{\circ} \\
\text { cons. } \\
\text { com } \\
\text { EV }\end{array}$ & $\begin{array}{l}\text { Potência } \\
\text { dos EVs } \\
\text { (KW) }\end{array}$ & $\begin{array}{l}\text { Potência } \\
\text { Reativa dos } \\
\text { EVs (KVAr) }\end{array}$ & $\begin{array}{l}\text { Potência } \\
\text { Total } \\
(K W)\end{array}$ & $\begin{array}{l}\text { Potência } \\
\text { Reativa } \\
\text { Total } \\
\text { (KVAr) }\end{array}$ \\
\hline alim01 & 1514 & 76 & 227 & 106 & 5696 & 1910 \\
\hline alim02 & 8416 & 421 & 1262 & 589 & 6300 & 2611 \\
\hline alim03 & 7776 & 389 & 1166 & 544 & 6517 & 2980 \\
\hline
\end{tabular}




\begin{tabular}{|l|l|l|l|l|l|l|}
\hline alim04 & 6376 & 319 & 956 & 446 & 4027 & 903 \\
\hline alim05 & 6052 & 303 & 908 & 424 & 3885 & 851 \\
\hline
\end{tabular}

Fonte: próprio autor

Figura 12 - Simulação da SE com $5 \%$ dos consumidores carregando seus BEV



Fonte: próprio autor 
Figura 13 - Resultados da SE com $5 \%$ dos consumidores carregando seus BEV

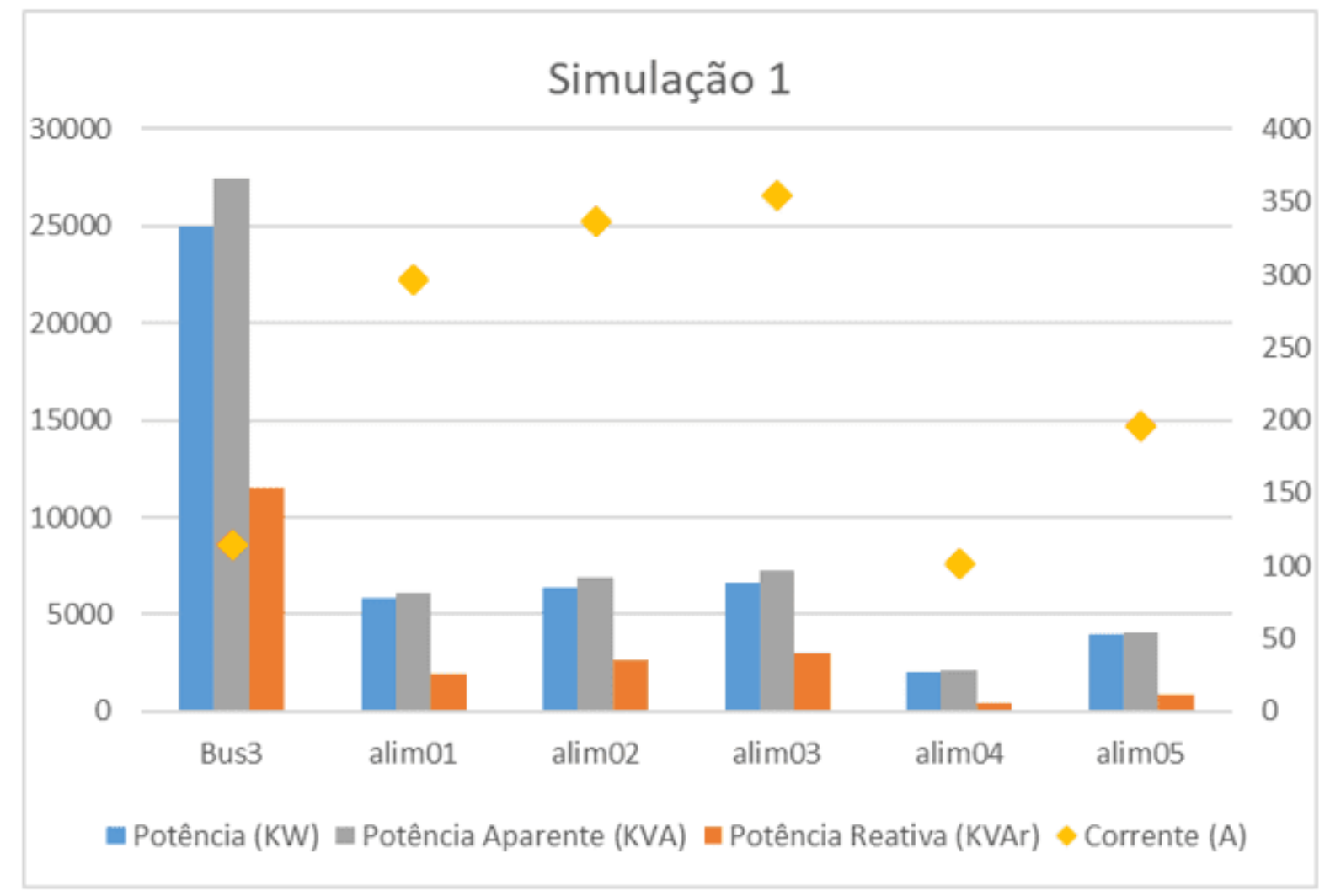

Fonte: próprio autor

Pela Figura 13 é possível observar que o transformador da SE operaria com 103,36\% da sua capacidade nominal excedendo assim sua capacidade total e em relação a corrente, nenhum alimentador apresentou correntes maiores do que a corrente máxima de 515 A. Ou seja, se apenas 5\% dos consumidores desta subestação decidirem carregar os seus EVs ao mesmo tempo no horário de ponta o transformar sofreria uma sobrecarga.

Na simulação 2 adota-se que 10\% dos consumidores fazem o carregamento dos EVs em horário de ponta. Os resultados são mostrados na Tabela 7 e nas Figuras 14 e 15. 
Tabela 7 - Dados da SE com 10\% dos consumidores carregando seus BEV

\begin{tabular}{|l|l|l|l|l|l|l|}
\hline Alimentador & $\begin{array}{l}n^{\circ} \\
\text { cons. }\end{array}$ & $\begin{array}{l}n^{\circ} \\
\text { cons. } \\
\text { com } \\
\text { EV }\end{array}$ & $\begin{array}{l}\text { Potência } \\
\text { dos EVs } \\
\text { (KW) }\end{array}$ & $\begin{array}{l}\text { Potência } \\
\text { Reativa dos } \\
\text { EVs (KVAr) }\end{array}$ & $\begin{array}{l}\text { Potência } \\
\text { Total } \\
(K W)\end{array}$ & $\begin{array}{l}\text { Potência } \\
\text { Reativa }\end{array}$ \\
$\begin{array}{l}\text { Total } \\
\text { (KVAr) }\end{array}$ \\
\hline alim01 & 1514 & 151 & 454 & 212 & 5923 & 2016 \\
\hline alim02 & 8416 & 842 & 2525 & 1178 & 7563 & 3200 \\
\hline alim03 & 7776 & 778 & 2333 & 1089 & 7684 & 3525 \\
\hline alim04 & 6376 & 638 & 1913 & 893 & 4984 & 1350 \\
\hline alim05 & 6052 & 605 & 1816 & 847 & 4793 & 1274 \\
\hline
\end{tabular}

Fonte: próprio autor

Figura 14 - Simulação da SE com 10\% dos consumidores carregando seus BEV

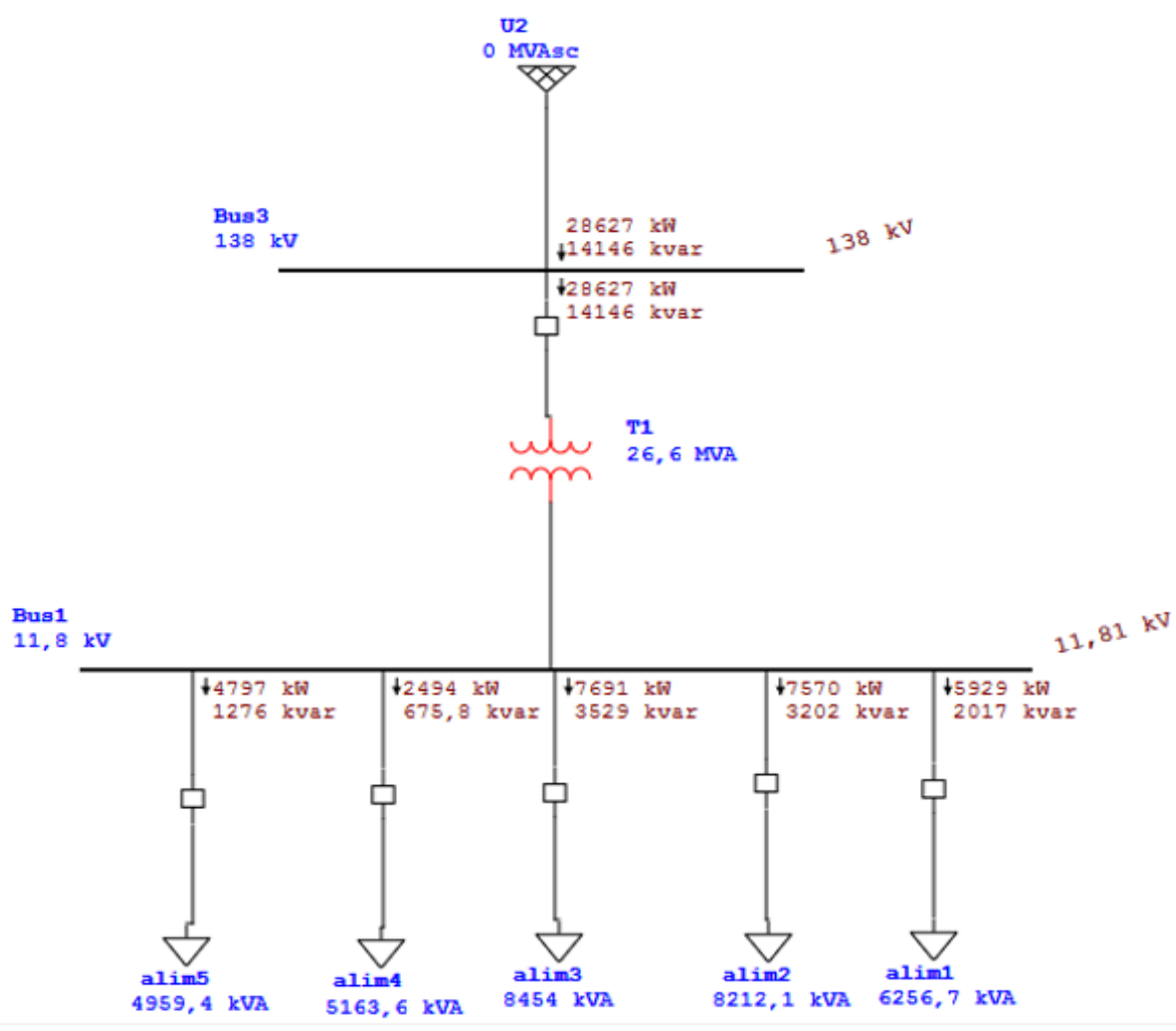

Fonte: próprio autor 
Figura 15 - Resultados da SE com 10\% dos consumidores carregando seus BEV

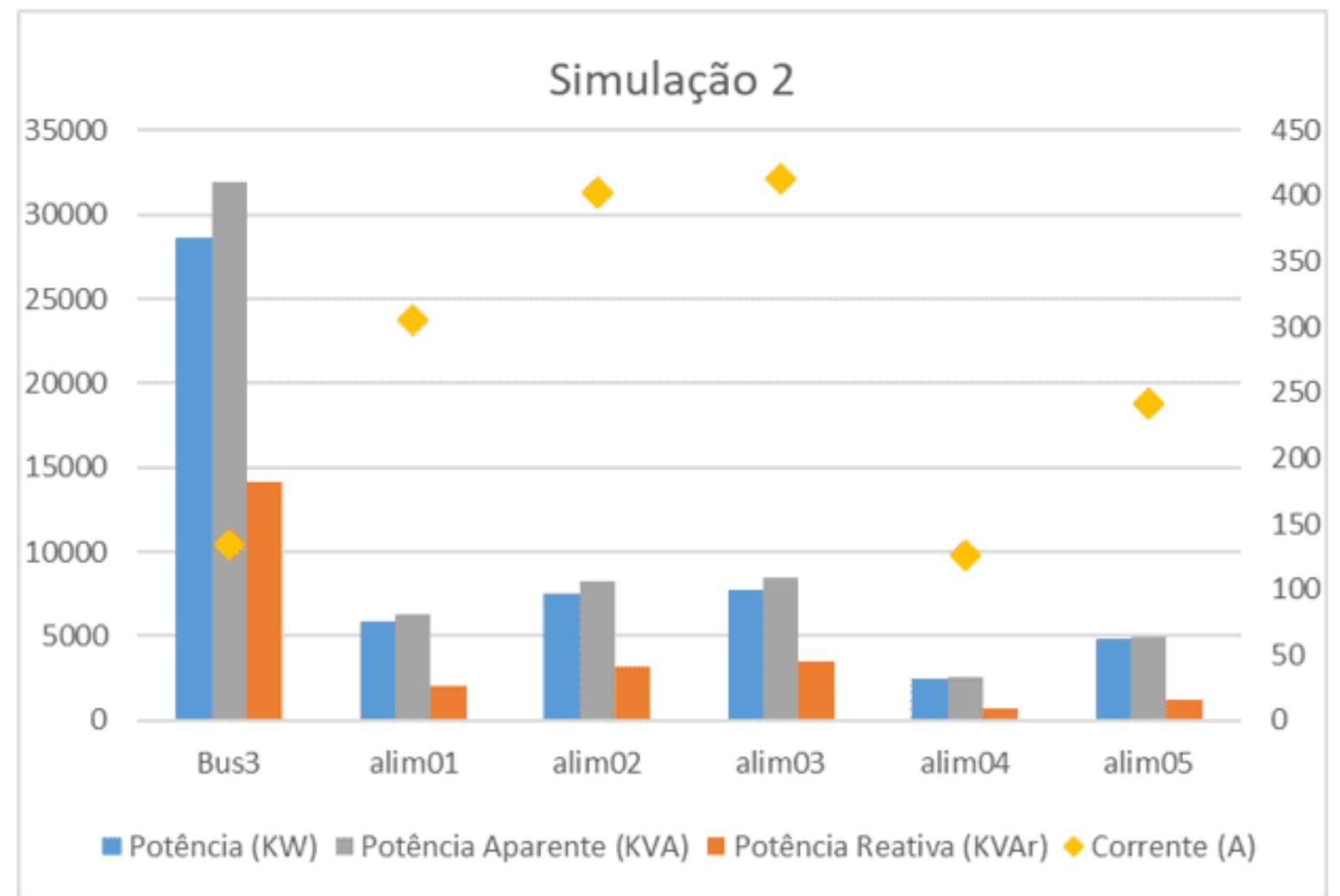

Fonte: próprio autor

No cenário proposto 2 verifica-se o transformador com uma capacidade de carga maior que sua capacidade nominal, a sobrecarga é $20,04 \%$ acima do valor nominal. A corrente máxima de nenhum alimentador foi atingida.

$\mathrm{Na}$ terceira simulação foi considerado a porcentagem de consumidores carregando seus EVs em 15\%. Os valores obtidos encontram-se Tabela 8 e nas Figuras 16 e 17.

Tabela 8 - Dados da SE com 15\% dos consumidores carregando seus BEV

\begin{tabular}{|c|c|c|c|c|c|c|}
\hline Alimentador & $\begin{array}{l}\mathrm{n}^{\circ} \\
\text { cons. }\end{array}$ & $\begin{array}{l}\mathrm{n}^{\circ} \\
\text { cons. } \\
\text { com } \\
\text { EV }\end{array}$ & $\begin{array}{l}\text { Potência } \\
\text { dos EVs } \\
(\mathrm{KW})\end{array}$ & $\begin{array}{l}\text { Potência } \\
\text { Reativa dos } \\
\text { EVs (KVAr) }\end{array}$ & $\begin{array}{l}\text { Potência } \\
\text { Total } \\
(\mathrm{KW})\end{array}$ & $\begin{array}{l}\text { Potência } \\
\text { Reativa } \\
\text { Total } \\
\text { (KVAr) }\end{array}$ \\
\hline
\end{tabular}




\begin{tabular}{|l|l|l|l|l|l|l|}
\hline alim01 & 1514 & 151 & 454 & 212 & 5923 & 2016 \\
\hline alim02 & 8416 & 842 & 2525 & 1178 & 7563 & 3200 \\
\hline alim03 & 7776 & 778 & 2333 & 1089 & 7684 & 3525 \\
\hline alim04 & 6376 & 638 & 1913 & 893 & 4984 & 1350 \\
\hline alim05 & 6052 & 605 & 1816 & 847 & 4793 & 1274 \\
\hline
\end{tabular}

Fonte: próprio autor

Figura 16 - Simulação da SE com 15\% dos consumidores carregando seus BEV

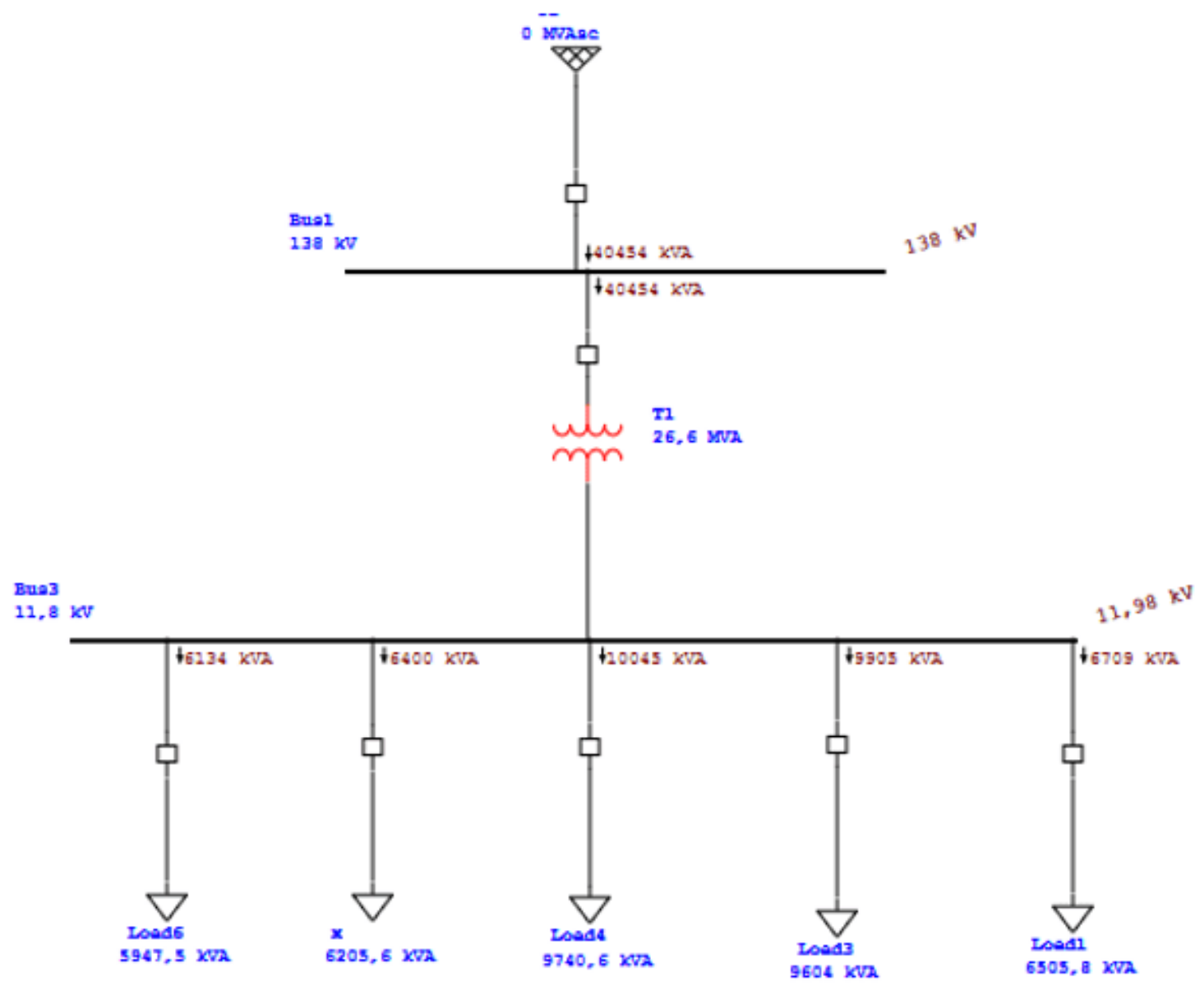

Fonte: próprio autor 
Figura 17 - Resultados da SE com 16\% dos consumidores carregando seus BEV

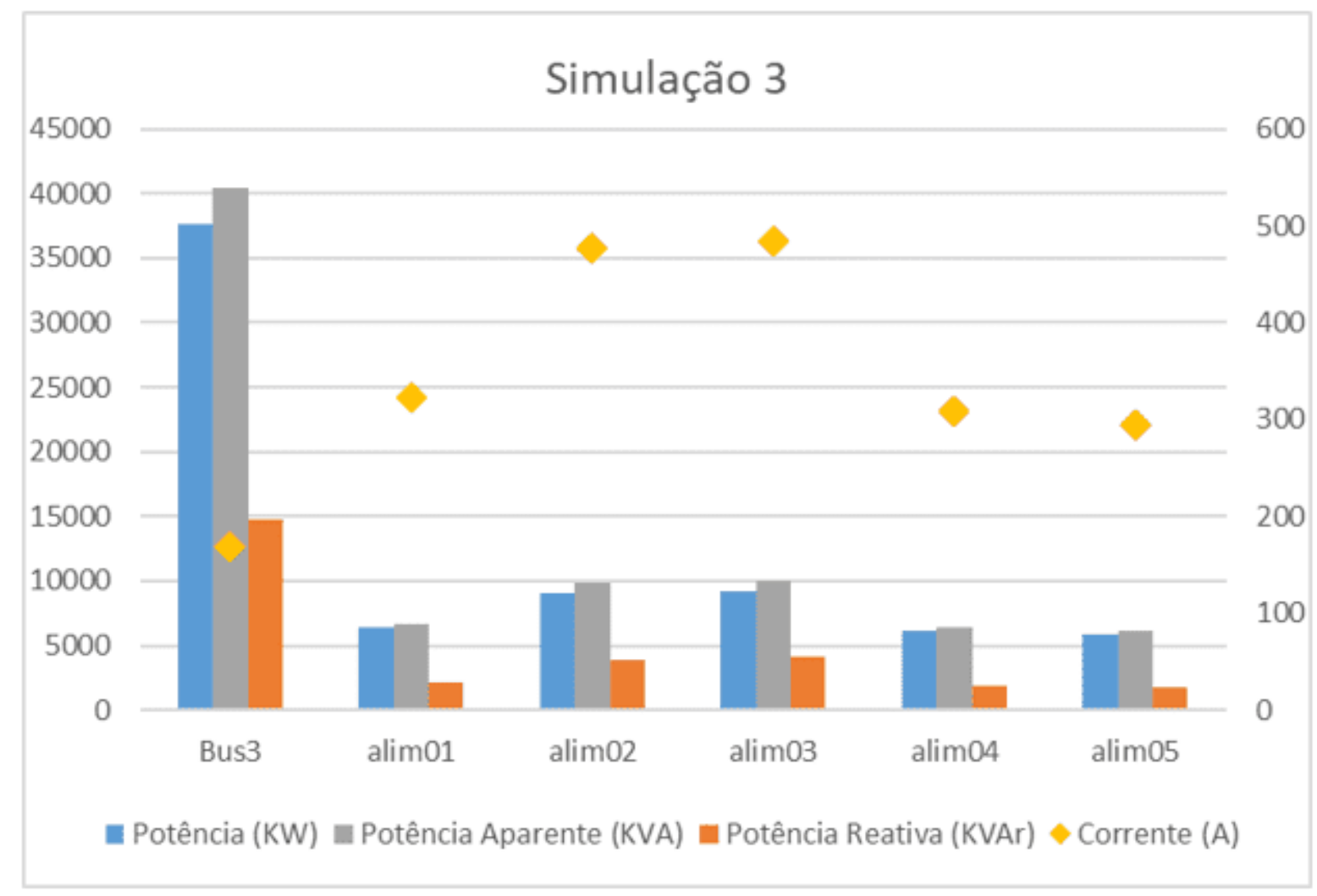

Fonte: próprio autor

Considerando que apenas $15 \%$ dos consumidores da SE em análise carregassem os EVs no horário de ponta o transformador da SE operaria com $152 \%$ da sua capacidade nominal excedendo assim sua capacidade total e em relação a corrente, como já ocorreu nas simulações, nenhum alimentador apresentou correntes maiores do que a corrente máxima de $515 \mathrm{~A}$.

A Figura 18 demonstra a evolução das cargas conforme o número de EV aumentam. 
Figura 18 - Comparação da potência requerida pelas cargas durante os cenários simulados



Fonte: próprio autor

Nas três simulações realizadas verificou-se que a capacidade nominal do transformador foi excedida, isso mostra que a subestação analisada não está preparada para a introdução de carros elétricos. Os alimentadores não tiveram as suas correntes excedidas, porém na simulação 3 os alimentadores 2 e 3 já se aproximam do valor nominal, tornando isso também um fator de atenção para um projeto de melhoria da SE no futuro.

\section{CONCLUSÃO}

Os valores mostrados no artigo indicam que atualmente o SIN tem uma geração de energia aproximadamente $20 \%$ acima do consumo nacional total, porém atualmente a geração de energia real representa apenas $42 \%$ da capacidade instaladas. Os métodos de geração de energia do SIN são: as usinas hidrelétricas, térmicas, eólicas, solar, biomassa e nuclear. Se todas elas funcionarem com 100\% da sua capacidade, com a introdução de EVs nos subsistemas estudados não será necessário um 
replanejamento no aumento de usinas e sim uma estratégia para aumentar a geração de energia para chegar próximo a capacidade total instalada.

De acordo com o estudo de caso 2, fica exposto que apesar da carga do EV ser considerada baixa, em altas quantidades causará um grande impacto nas redes de transmissão de média tensão. Um ponto de atenção durante os resultados é que a corrente não atinge o valor máximo, porém as empresas responsáveis pelas SE possuem um limite de corrente usual para redes de 11,9KV é de 325A. Deste modo todas as simulações nos mostram que dois alimentadores ultrapassam este limite usual trazendo a necessidade de fazer uma redistribuição de carga ou realizar uma ampliação da subestação. Quando existe a necessidade de uma ampliação da rede o consumidor final pode ter um aumento na tarifa, isso nos mostra que a utilização de EVs gera um impacto direto no bolso do consumidor final, desde que o carregamento da bateria for realizado pelo SIN. A geração de energia através de placa solares é uma das opções que podem auxiliar na redução de carga na subestação, porém devese realizar um estudo verificando os benéficos e custos desta tecnologia.

\section{REFERÊNCIAS}

ARAÚJO; T. L. V., Veículos Elétricos: Impactos na Rede Elétrica, Dissertação (Mestrado) - Universidade de Trás-os-Montes e Alto Douro, Vila Real, 114f, 2017.

BARRETO, G., Veículo elétrico à bateria: contribuições à análise de seu desempenho e seu projeto, Dissertação (Mestrado) - Universidade Estadual de Campinas, Campinas, 360f, 1986.

CHAN, C. C. e CHAU, K.T., Modern Electric Vehicle Technology, Oxford University Press, New York, 2001.

CPFL - Normas Técnicas - https://www.cpfl.com.br/atendimento-aconsumidores/orientacoes-tecnicas/publicacoes-tecnicas/Paginas/normastecnicas.aspx, Acesso em outubro, 2018. 
EPE - Empresa de Pesquisa Energética, Anuário Estatístico de Energia Elétrica 2017 - Ano base 2016, Disponível em: http://www.epe.gov.br >. Acesso em: 07 out. 2018.

ELECTRIFY, I., The BMW i3 Electric Vehicle, Disponível em : https://www.bmwusa.com/vehicles/bmwi/i3/sedan/overview.html, acesso em outubro, 2018.

JORNAL O SUL, Único carro elétrico no Brasil, BMW i3 pode rodar até 160 quilômetros sem uma gota de gasolina, Disponível em: < http://www.osul.com.br/unico-carro-eletrico-no-brasil-bmw-i3-pode-rodar-ate-160quilometros-sem-uma-gota-de-gasolina/>. Acesso em: 29 out. 2018.

LOPES, J., Metodologias de dimensionamento e de gestão de fontes de energia para veículos elétricos, Tese (Doutorado) - Universidade Estadual de Campinas, Campinas, 180p, 2012.

ONS - Operador Nacional do Sistema Elétrico, Mapas para Download, Disponível em: <http://ons.org.br/paginas/sobre-o-sin/mapas>. Acesso em: 26 abr. 2018.

ORANGE \& ROCKLAND, Electric Vehicles. Disponível em: https://www.oru.com/en/our-energy-future/technology-innovation/electric-vehicles>. Acesso em: 25 mai. 2018.

REVISTA AUTO ESPORTE, Avaliação: Renault Zoe Z.E. Disponível em: < https://revistaautoesporte.globo.com/Analises/noticia/2015/01/avaliacao-renault-zoeze.html>, Acesso em: 29 out. 2018.

TIE, S.F. e TAN, C.W. A review of energy sources and energy management system in electric vehicles, Renew Sustain Energy Rev, 2013.

YONG, J. Y. et al, A review on the state-of-the-art technologies of electric vehicle, its impacts and prospects, Renewable and Sustainable Energy Reviews, September, 2015 , disponível em 
https://www.sciencedirect.com/science/article/abs/pii/S1364032115004001, acesso em maio, 2018.

Enviado: Outubro, 2019.

Aprovado: Outubro, 2020. 